\title{
On the assessment of the dust-air masses distribution regularity in the workshops of the reinforced concrete products' manufacturing
}

\author{
Aleksandr Evtushenko ${ }^{1 *}$, Yulia Startseva ${ }^{2}$, Aleksandr Khoperskov $^{2}$, and Valeriy Azarov ${ }^{2}$ \\ ${ }^{1}$ Don State Technical University, 344002, Rostov-on-Don, Russian Federation \\ ${ }^{2}$ Volgograd State Technical University, 400006, Volgograd, Russian Federation
}

\begin{abstract}
Workshops for the reinforced concrete products manufacturing belong to the type of structures, which in some cases can be called stacked $[1,2$,$] . Technological platforms with equipment and workplaces located on$ them are located at different elevations and have openings between themselves.
\end{abstract}

\section{Introduction}

The air exchange calculation in these workshops by the mass of emitted harmful substances is presented by the formula (1) [3]

$$
L=L_{w, Z}+\frac{m_{p o}-L_{w, Z}\left(q_{w, z}-q_{i n}\right)}{q_{l}-q_{i n}}
$$

where

$L_{w, z}$-is the air consumption, removed from the serviced or working area of the room by local suction systems, and for technological needs, $\mathrm{m}^{3} / \mathrm{h}$;

$m_{p_{o}}$ is theconsumption of each harmful or explosive substance entering the roomair, $\mathrm{mg} / \mathrm{h}$;

$q_{w, z}, q_{l}$ define the concentration of a harmful or explosive substance in the air removed, respectively, from the serviced or working area of the premises and outside of it, $\mathrm{mg} / \mathrm{m}^{3}$;

$q_{i n}$ is theconcentration of harmful or explosive substances in the air supplied to the room, $\mathrm{mg} / \mathrm{m}^{3}$.

Due to the presence of open apertures between the technological sites of the workshops in question, there is an overflow of hazards and, as a result, a change in the harmful substances'concentration in the volume of a particular site.

\section{Main part}

To assess the flow of dust-air masses between technological sites, it is necessary to solve the following problems:

- -assessment of the equipment tightness and the efficiency of the dedusting system;

\footnotetext{
* Corresponding author: a.evtushenko@mail.ru
} 
- analysis of the dispersed composition of dust emitted into the volume of the workshop;

- determination of the hover speed as a function of the dust particles' diameter;

- assessment of the air flows' movement regularity inside the technological site.

The air flows'movement within the same site depends not only on the technological equipment location and its intensity of harmful substances' emission, the speed of their spread, but also on the schemes of organizing the airsupply.

The calculation of the sedimentation rate of dust particles of concrete goods production facilitiesin the air was performedby sedimentation method. Based on the dustdispersion analysis results (Figure 1), the graphs that represent the dependences of the settling rate of dust particles on their equivalent diameter in a logarithmic grid, Figure 2 were obtained.

$$
\mathrm{D}(\mathrm{dh}), \%
$$

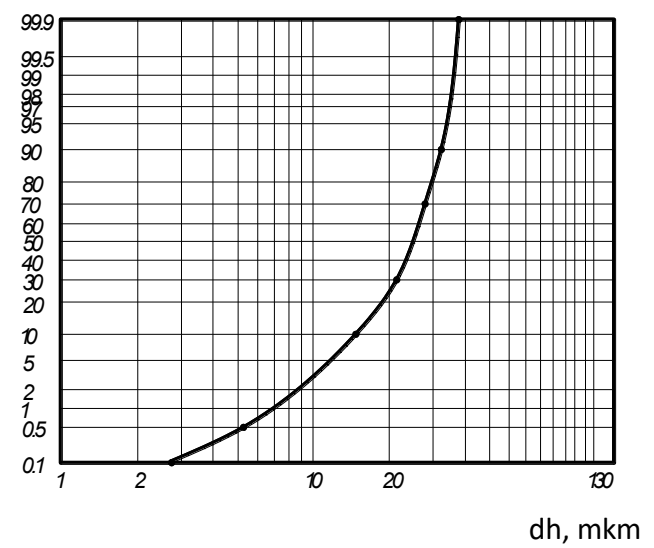

Fig. 1. The weighted average integral function of the particles mass distribution by diameter in the concrete mixing department of the concrete goods plant

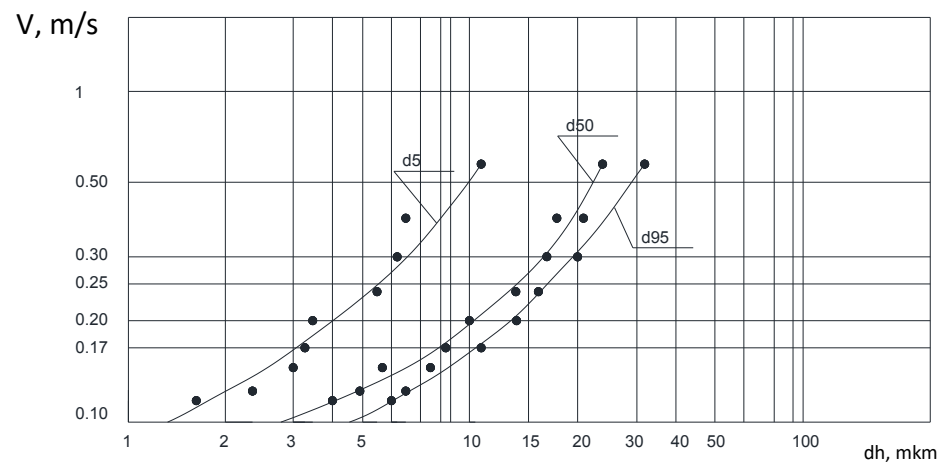

Fig. 2. Dependence of the settling rate on the equivalent particle diameter, presented in a logarithmic grid: 1 - minimum equivalent diameters; 2 - median equivalent diameters; 3 - maximum equivalent diameters.

As a result of studies of the dependence of the settling rate on the equivalent diameter of a dust particle that is emitted during the production of reinforced concrete products, it can be seen that at a speed of $0.5 \mathrm{~m} / \mathrm{s}$, the particles have the largest size equal to $28 \mu \mathrm{m}$, an average size of $22 \mu \mathrm{m}$ and the smallest size of $17 \mu \mathrm{m}$; at a velocity of $0.3 \mathrm{~m} / \mathrm{s}$, the particles have the largest size $19 \mu \mathrm{m}$, the average size $15 \mu \mathrm{m}$ and the smallest size $5 \mu \mathrm{m}$; at a velocity of $0.1 \mathrm{~m} / \mathrm{s}$, the particles have the largest particle size of $5 \mu \mathrm{m}$, an average size of $4 \mu \mathrm{m}$ and the smallest particle size of $2 \mu \mathrm{m}$. 


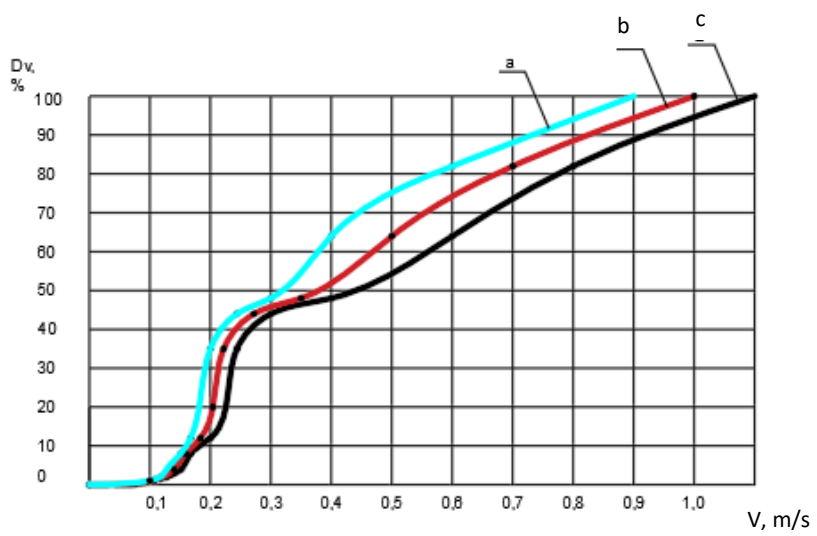

Fig. 3. The integral function of the dust particles mass distribution by sedimentation rates for: a above-bunker compartment, $\mathrm{b}$ - dosing compartment, $\mathrm{c}$ - concrete mixing compartment.

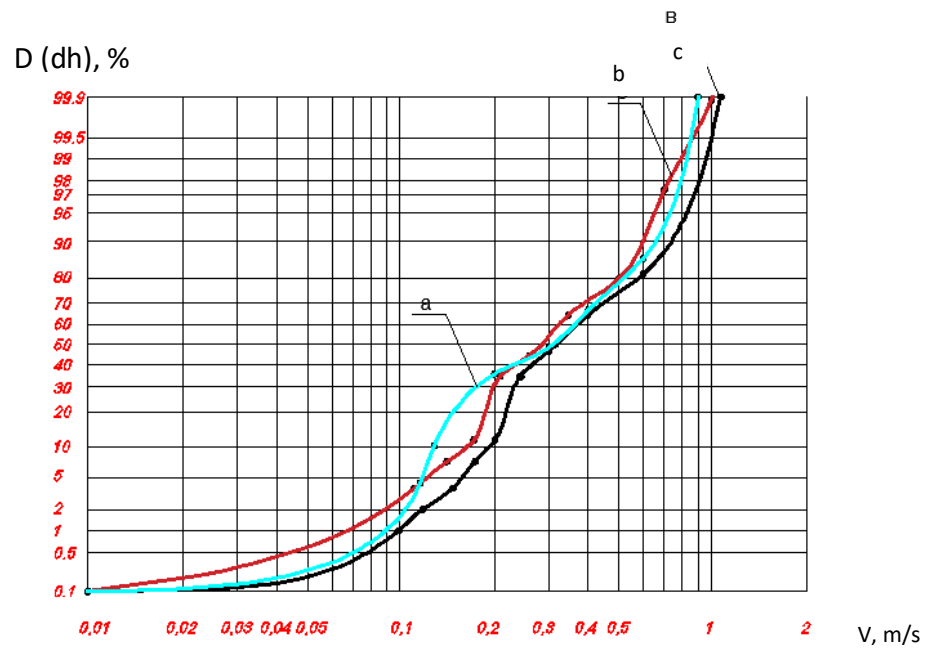

Fig. 4. The distribution function of the dust particles mass by sedimentation rates for: a - abovebunker compartment, b - dosing compartment, c- concrete mixing compartment.

For medium-heavy work of category 2 during the warm season, the maximum permissible air speed at workplaces is $0.5 \mathrm{~m} / \mathrm{s}$, taking into account the analysis of the dust settling rates in the concrete goods production workshop, it can be seen that at an air velocity of $0.4 \mathrm{~m} / \mathrm{s}$, dust particles with a size of up to 15 microns will be transferred to the technological sites located above.

On the example of the concrete mixing department, a 3D model was built and the air currents were modeledin it. To calculate the trajectory of particle motion, we used the SPH method [8,9], which, with a high degree of accuracy, gives an idea of the dust particlesmotionnature. The smoothed particle algorithm is convenient for setting boundary conditions on solid surfaces with complex geometry in three-dimensional space. The use of the SPH method is effective for self-consistent modeling of gas flow and dynamics of air pollutants, and this approach is common for predicting air pollutants from various anthropogenic sources at various spatial scales of the atmosphere [12]. A parallel implementation for Nvidia Tesla GPUs is described in [11]. When simulating the movement $[4,5,6]$ of air flows, a lateral supply of supply air was organized into the 
working area at a velocity of $2 \mathrm{~m} / \mathrm{s}$ at the outlet from the air distributor. Figure 5 shows the trajectories of the air flow in the volume of the room, the average velocity of which is about $0.4-0.7 \mathrm{~m} / \mathrm{s}$.
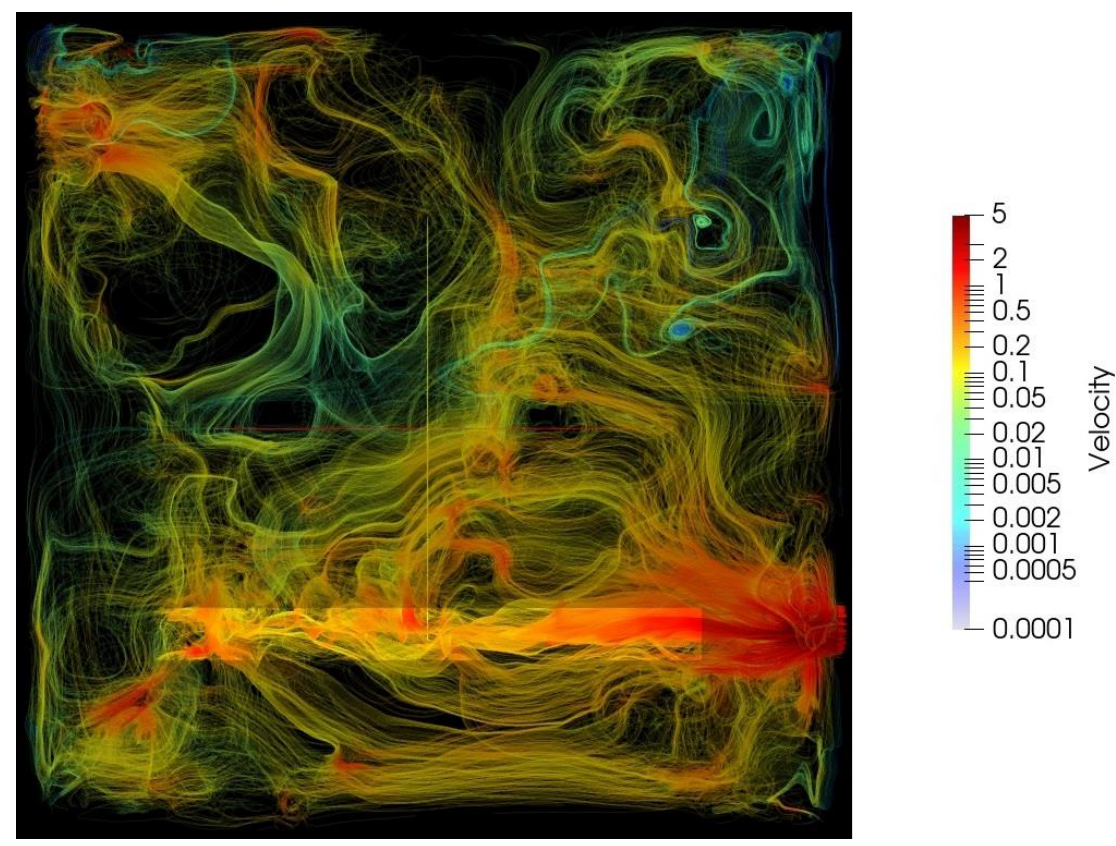

Fig. 5. The trajectory and the air flowvelocity at the technological site of the mixing unit

In rooms with very large technological equipment (more than 3 meters high), which include workshops for the reinforced concrete products manufacturing, the following supply air schemes are recommended: directly into the working area; oblique jets into the area between the technological equipment; concentrated with the use of directing nozzles [7].

The diagrams of the air distribution organization (Figure 6, 7, 8,9) show the movement of dust-air masses, where the blue arrows represent the fine dust particles, and red arrows represent the coarse dust particles.

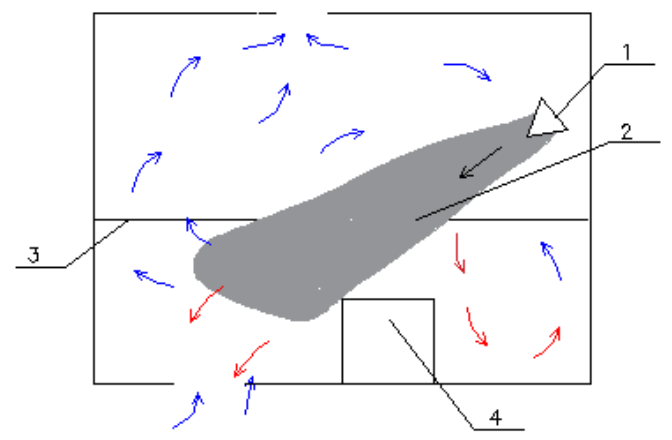

Fig. 6. Scheme of supplying air to the workshop volume with inclined jets at an angle $45^{\circ}$ to the floorplane; the air diffuser is located above the working area. 1 - air distributor; 2 - distribution area of the supply stream; 3 - the boundary of the roomworking area; 4- dust emissionsource 


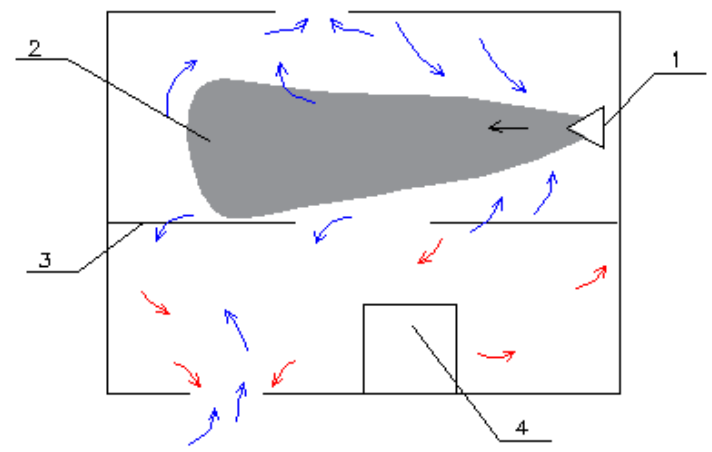

Fig. 7. Scheme of supplying air to the workshop volume with inclined jets parallel (at an angle of $180^{\circ}$ ) to the floor plane; the air diffuser is located above the working area. 1 - air distributor; 2 distribution area of the supply stream; 3 - the boundary of the roomworking area ; 4- dust emissionsource

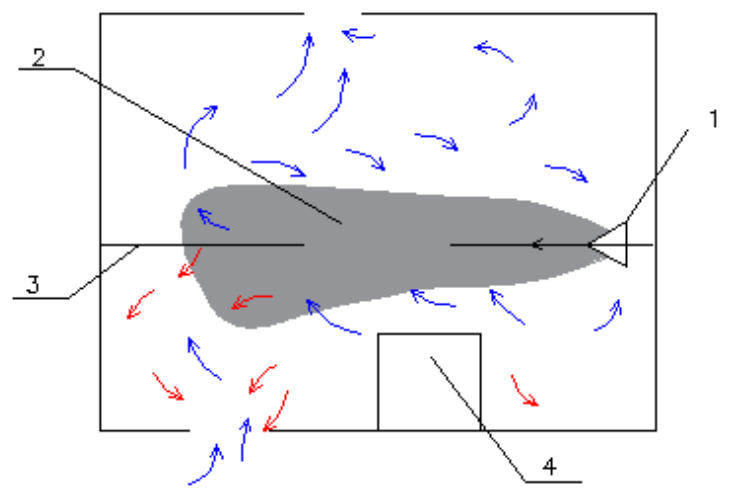

Fig. 8. Scheme of supplying air to the workshop volume with inclined jets parallel (at an angle of $180^{\circ}$ ) to the floor plane; the air diffuser is located at the level of the working area. 1 - air distributor; 2 - distribution area of the supply stream; 3- the boundary of the roomworking area; 4- dust emissionsource

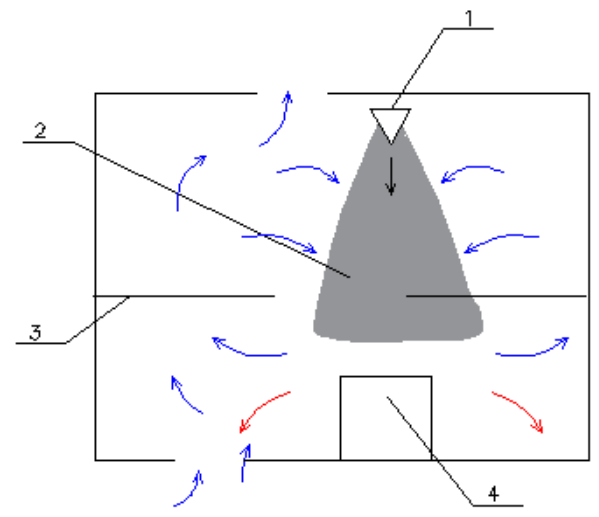

Fig. 9. Scheme of supplying air into the volume of the workshop with vertical jets downward (at an angle of $90^{\circ}$ ) to the floor plane; the air diffuser is located at the working arealevel. 1 - air distributor; 2 - distribution area of the supply stream; 3- the boundary of the roomworking area; 4- dust emissionsource 
With the above-listed methods of supplying the supply air, several rings of air and airdust flows are formed. The circular air movement creates an additional take-off of dust particles from horizontal surfaces, and near enclosing structures or technological equipment -the stagnant zones with an increased concentration of dust.

Figures 10.11 show a diagram of the air supply discharge to the working area at low velocity.

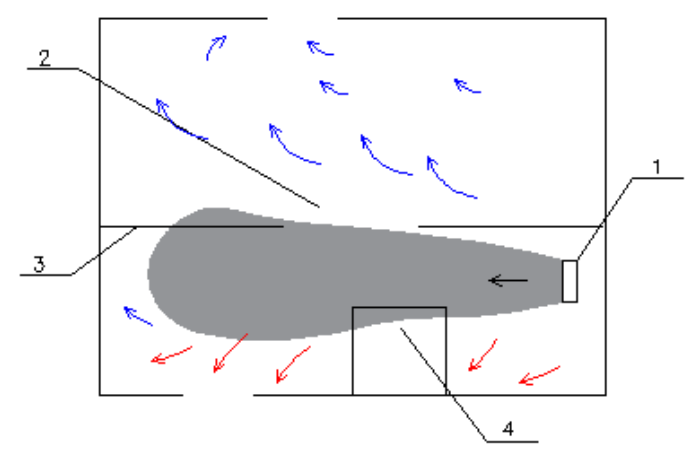

Fig. 10. Scheme of supplying air to the workshop volume with inclined jets parallel (at an angle of $180^{\circ}$ ) to the floor plane at low velocity; the air distributor is located at the level of the working area on the opposite side from the interfloor opening. 1 - air distributor; 2 - distribution area of the supply stream; 3- the boundary of the roomworking area; 4- dust emissionsource

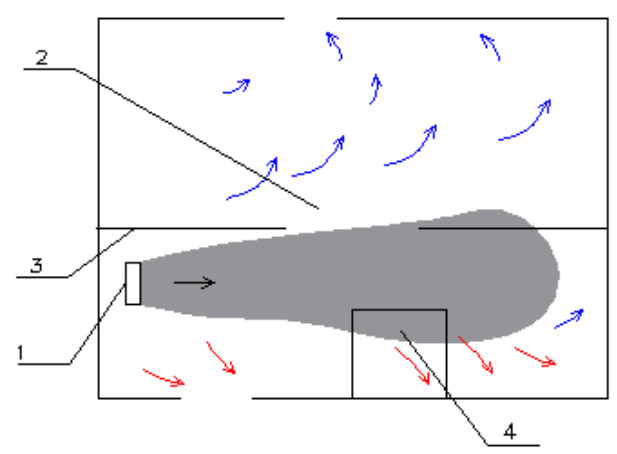

Fig. 11. Scheme of supplying air to the workshop volume with inclined jets parallel (at an angle of $180^{\circ}$ ) to the floor plane at low velocity; the air distributor is located at the level of the working area from the side of the interfloor opening. 1 - air distributor; 2 - distribution area of the supply stream; 3the boundary of the roomworking area; 4- dust emissionsource

\section{Conclusion}

Thus, when air is supplied to the working area with low-velocity streams, the repeated flinging up of already settled dust is excluded, thereby reducing the movement of dust from one technological site to another.

\section{References}

1. Yu.VStartseva, V.Ch. Meskhi, V.N. Azarov, A.I. Yevtushenko, On creating optimal working conditions in multi-storey buildings of concrete mixing plants, International 
Scientific and Practical Conference Environmental Risks and Safety in Mechanical Engineering (ERSME-2020) 20-22 October 2020, Rostov-on-Don, Russia / Don State Technical University. - IOP Publishing, 2020

2. Yu.V. Startseva, Bulletin of the Volgograd State University of Architecture and Civil Engineering. Series: Construction and architecture 50 (69), 122-130 (2017).

3. BC 60.13330 Building Code Heating, ventilation and air conditioning.

4. Yu.V. Shafran, A.V. Khoperskov, Science Journal of VolSU. Mathematics. Physics 2 (33), 52-62 (2016)

5. Yu.V. Saffran, M.A. Butenko, N.M. Kuzmin, A.V. Khoperskov, Modern information technology and IT education 1 (9), 509-517 (2014).

6. J.E. Hilton, P.W. Cleary, Int J Numer Meth Fluid 72, 528-549 (2013).

7. M.I. Grimitlin, Air distribution in rooms (Stroyizdat, Moscow, 1982).

8. A. Titov, S. Khrapov, V. Radchenko, A. Khoperskov, Communications in Computer and Information Science 965, 173-184 (2019).

9. L. Antonelli, E. Francomano, F. Gregoretti, Applied Mathematics and Computation 125482 (2020).

10. A. Stohl, C. Forster, A. Frank, P. Seibert, G. Wotawa, Atmospheric Chemistry and Physics 5, 2461-2474 (2005).

11. S. Khrapov, A. Khoperskov, S. Khoperskov, J Phys Conf 1392, 012041 (2019). 